ISSN: 2539-3804 @(1) $\Theta$

\title{
(Re)producción de lenguaje escrito en el aprendizaje inicial de la escritura de textos
}

\author{
Angélica Sepúlveda(C) \\ Universidade do Estado do Mato Grosso \\ Juara, Brasil \\ Ana Teberosky ${ }^{\circ}$ \\ Universidad de Barcelona \\ Barcelona, España
}

\section{Resumen}

En este artículo reflexionamos sobre la actividad de reproducción o reescritura de textos como un procedimiento específico para enseñar y aprender lenguaje escrito. Presentamos una descripción detallada del lenguaje reproducido y reformulado por dos niños de Segundo de Primaria al reescribir la historia de un libro de literatura infantil. A partir del análisis de estos ejemplos consideramos la importancia de la entrada lingüística y el papel de la producción de lenguaje en el proceso de aprendizaje. Finalmente, destacamos las condiciones didácticas en las que tuvo lugar el tipo de producción infantil analizada: clases en las que se leen, comentan, recuentan y reescriben obras de literatura infantil. Palabras clave: alfabetización; lenguaje escrito; reescritura.

\begin{abstract}
(Re)production of written language in the initial learning of writing texts

In this paper, we reflect upon the activity of text reproduction or rewriting, as a specific procedure to teaching and learning written language. We present a detailed description of the language reproduced and reformulated by two second graders when rewriting a story from a children's literature book. From the analysis of these examples we consider the importance of linguistic input and the role of language reproduction in the learning process. Finally, we highlight the teaching conditions under which the type of children's production analyzed took place: classrooms where children's literature books are read, discussed, recounted and rewritten.
\end{abstract}

Key words: literacy; written language; rewriting. 


\section{Résumé}

\section{(Re)production du langage écrit dans l'apprentissage initial de l'écriture de texte}

Dans cet article, nous réfléchissons à l'activité de reproduction ou de réécriture des textes comme une procédure spécifique pour enseigner et apprendre la langue écrite. Nous présentons une description détaillée de la langue reproduite et reformulée par deux enfants de deuxième année lors de la réécriture d'une histoire. À partir de l'analyse de ces exemples, nous considérons l'importance de l'apport linguistique et le rôle de la production de langage dans le processus d'apprentissage. Enfin, nous mettons en évidence les conditions didactiques dans lesquelles s'est déroulé le type de production enfantine analysée : des classes dans lesquelles les livres de littérature pour enfants sont lues, discutées, racontées et réécrites.

Mots-clés : alphabétisation ; langue écrite ; réécriture. 


\section{SOBRE LAS AUTORAS}

\section{Angélica Sepúlveda}

Fonoaudióloga de la Universidad Nacional de Colombia. Doctora en Psicología de la Educación por la Universidad de Barcelona. Interesada en la comprensión del desarrollo del lenguaje letrado y el aprendizaje inicial de la escritura de textos. Colaboradora del proyecto Aprender a estudiar textos, de la organización no gubernamental brasileña Laboratório de Educação. Profesora del curso de Pedagogía de la Universidade do Estado do Matogrosso.

Correo electrónico: luz.angelica@unemat.br

\section{Ana Teberosky}

Catedrática de Psicología Evolutiva y de la Educación y profesora Honorífica de la Universidad de Barcelona (España). Su investigación está relacionada con el aprendizaje del lenguaje y con los proyectos psicopedagógicos de enseñanza desde una perspectiva constructivista. Ha publicado varios libros y artículos, y material de difusión digital sobre el aprendizaje del lenguaje y de la lectura y la escritura en España y América Latina. Correo electrónico: ateberosky@ub.edu

\section{Cómo CITAR ESTE ARTÍCULO}

Sepúlveda, A., \& Teberosky, A. (2021). (Re)producción de lenguaje escrito en el aprendizaje inicial de la escritura de textos. Lenguaje, 49(1), 198-225. https://doi.org/10.25100/lenguaje.v49i1.8800. 


\section{INTRODUCCIÓN}

\section{La capacidad infantil de reproducción de textos}

La capacidad infantil de reproducción de amplias unidades discursivas, tanto en lo oral como en lo escrito, ha sido documentada por diferentes tradiciones de estudios psicológicos, psicopedagógicos y lingüísticos. Los estudios psicológicos sobre el desarrollo de la memoria muestran que los niños de 5 a 7 años son capaces de reproducir cuentos, canciones, poemas, casi literalmente después de un cierto tiempo de exposición (Rubin, 1995). También, los estudios psicopedagógicos con niños preescolares sostienen que, en la situación de simular leer o de recontar historias conocidas, son capaces de producir extensas unidades discursivas (Pappas y Brown, 1987; Teberosky, 1992). En estos estudios se ha mostrado que los niños conservan aspectos del texto tales como el tema y las relaciones secuenciales de los eventos de la historia, así como elementos que aseguran la conexión sintáctica y semántica del texto; también que reproducen la organización de comienzo y final e incluso algunas expresiones lexicales de forma literal.

Esta capacidad infantil de recontar se da en la situación de uso de los textos. Por ejemplo, en situaciones experimentales o en situaciones didácticas, se ha mostrado que la capacidad de recuento aparece tanto en lo oral como en la actividad de reescritura de cuentos leídos por el adulto (Ferreiro et al., 1996; Puranik et al., 2007; Sepúlveda, 2012; Teberosky y Sepúlveda, 2009, 2019). En estos trabajos, la actividad de reescribir un texto fuente ha permitido a los investigadores conformar un corpus de escrituras infantiles en el que analizar los procesos de aprendizaje. Así, los textos infantiles producidos en el paradigma de la reescritura de textos han permitido analizar cómo avanzan los niños en la construcción de conocimientos del texto y de disposición gráfica (por ejemplo, la segmentación de palabras, de relaciones entre puntuación y organización textual, de unidades textuales que estimulan el aprendizaje de las convenciones escritas, entre otros).

Con el procedimiento de reescritura de textos, nuestros estudios (Sepúlveda, 2012; Sepúlveda y Teberosky, 2011; Teberosky y Sepúlveda, 2009, 2019) han llamado la atención sobre la creciente capacidad de apropiación y reproducción de diversidad de aspectos de los textos-fuente. En una investigación longitudinal en la que analizamos las producciones escritas de un grupo de diez niños durante los dos primeros cursos de Educación Primaria (Sepúlveda, 2012; Teberosky y Sepúlveda, 2009) documentamos que cuando los niños tienen la oportunidad repetida de producir a partir de una fuente definida -reescribiendo cuentos de literatura infantil, leídos y comentados en el aulaaprenden a escribir textos cada vez más extensos (medido en el número total de palabras) y más complejos (medido en el número total de palabras diferentes y de conjunciones coordinantes y subordinantes), que incorporan un mayor número de convenciones gráficas (medido en el número de signos de puntuación) y formas de organización discursiva (marcadores y conectores discursivos); y que van reproduciendo una mayor 
proporción de palabras y expresiones del texto fuente, fenómeno que referimos como tendencia a la similitud (Sepúlveda, 2012).

\section{Reproducción, reformulación y aprendizaje del lenguaje}

La reproducción de un discurso se ha observado en situaciones muy variadas de uso del lenguaje: así por ejemplo en las situaciones comunicativas de intercambios verbales entre adultos (Tannen, 1987), en los intercambios verbales entre adultos y niños (Chouinard y Clark, 2003) y en el tratamiento de dificultades de lenguaje (De Weck, 2000). En muchas de estas situaciones de interacción, la reproducción por parte del adulto puede tener objetivos de corrección. Ocurre también en la adquisición de la lengua materna por parte de los niños (Keenan, 1975; Martinot, 2003; Veneziano et al., 1990) y en el aprendizaje de una segunda lengua (Ellis y Sheen, 2006). Apoyadas en nuestros estudios previos, sostenemos que también en el aprendizaje de la escritura de textos la reproducción de discursos juega un papel importante (Sepúlveda, 2012; Teberosky y Sepúlveda, 2009).

La noción de reproducción está emparentada con muchas otras nociones: por ejemplo, con las nociones de reformulación, imitación, parodia, reanudación, glosa, corrección, reconstrucción, resumen, comentario, reescritura, reporte, paráfrasis, citación, alusión, incluso copia o plagio. A pesar de la diversidad de nociones y de situaciones (Kara, 2007), los componentes básicos son dos, un enunciado o texto fuente y otro reproducido, y una cierta equivalencia entre ambos. Varios lingüistas se han interesado en analizar las relaciones de equivalencia o de correspondencia entre ambos (Bernicot et al., 2006; Martinot, 2003). De acuerdo con estas relaciones se puede considerar que algunas reproducciones son reformulaciones muy cerca de la repetición literal, otras están más cerca de la paráfrasis; unas se producen en oral, otras en escrito; unas ocurren dentro de un mismo discurso (intratextual) y otras entre diferentes discursos (intertextual). Pero dada su productividad queda claro que se trata de un procedimiento muy frecuente y con una función dentro del aprendizaje y uso del lenguaje.

Varios autores coinciden en que el lenguaje que los niños reciben del adulto (input) no es analizado sino comprendido, mientras que el lenguaje que los niños usan o producen (output) es una fuente privilegiada para el análisis. Swain (1995) afirma que el proceso de producción estimula a los aprendices a moverse de estrategias semánticas, prevalentes en la comprensión, a estrategias más reflexivas y metalingüísticas. Del mismo modo Elbers (2000) demostró la importancia de la producción en la adquisición del lenguaje, que nosotros extendemos como procedimiento válido para la alfabetización.

De esta manera proponemos que para aprender lenguaje escrito y a escribir textos, los textos se lean, relean, comenten y recuenten en la clase para realizar posteriormente una reescritura. Consideramos que las apropiaciones infantiles se dan como un subproducto de esta secuencia de actividades, y en particular de la reescritura, que a su 
vez es una tarea emparentada con otros procedimientos lingüísticos más generales, que han sido descritos como reformulación, atrincheramiento o priming.

El concepto de reformulación ha sido definido como un proceso de repetición de un enunciado o discurso anterior que mantiene una parte invariante y una parte variante (Martinot, 2003). O como el conjunto de transformaciones que un discurso admite de una única y misma fuente para devenir otro equivalente (Peytard, 1984).

El concepto de atrincheramiento consiste en el afianzamiento de una unidad lingüística como patrón cognitivo o de rutina en la mente del usuario de la lengua (Tomasello, 2003). La frecuencia de ocurrencia determina el nivel de afianzamiento y la similitud estructural que subyace a la aparición de patrones gramaticales generales (o esquemas). Por tanto, una palabra familiar o una combinación de palabras están afianzadas en la mente del usuario en función de la frecuencia con la que se han escuchado. Esto depende tanto de la frecuencia relativa del input como de la cantidad de experiencia que el usuario ha tenido, es decir, las oportunidades de uso.

El priming (imprimación) es definido por Hoey (2004) de la siguiente manera:

La noción de priming se toma de la psicología y en este contexto significa que nuestros encuentros con una palabra nos acostumbran a esperar que se use de cierto modo, de tal manera que estos usos potenciales se convierten en parte de nuestro conocimiento de la palabra y en cierta medida limitan la forma en que es probable que utilicemos la palabra nosotros mismos. (p. 174) ${ }^{1}$.

El concepto de imprimación explica por qué un estímulo, por ejemplo una palabra o una frase particular, aumenta la probabilidad de que el oyente reproduzca esa palabra o una frase relacionada o idéntica a la que ha escuchado (Savage et al., 2006). Los estudios sobre la imprimación han demostrado que hay similitudes prosódicas o semánticas y también reutilización léxica del discurso escuchado. Esta reutilización léxica tiene efectos, por ejemplo, cuando se comparte un verbo entre el discurso escuchado y su posterior producción: se aumenta la probabilidad de replicación sintáctica, lo que da como resultado el denominado efecto de "impulso léxico" (lexical boost en inglés) (Pickering y Branigan, 1998; Rowland, et al., 2012).

Por tanto, mientras que en una situación de comprensión -como durante la escucha de un texto leído en voz alta- hay mayor atención al significado, en la situación de producción -como en la reescritura del texto escuchado- el proceso es más reflexivo y analítico. Esos autores sostienen que además de comprender el input, la adquisición del lenguaje implica algún tipo de trabajo analítico para la producción: sea en la adquisición inicial del lenguaje oral, como lo sostienen Tomasello (1992), Clark (1993) y Elbers (2000);

${ }^{1}$ Cita traducida por las autoras. 
sea en la primera (Elbers, 2000) o en la segunda lengua, según Swain (1995), así también en el lenguaje escrito (Ferreiro, 2002; Teberosky, 1992).

A continuación presentamos dos ejemplos de escrituras infantiles con el objetivo de observar detalladamente los procedimientos de reproducción de discursos utilizados por los niños en la actividad de reescritura de textos y reflexionar sobre los principios teóricos citados en este apartado.

\section{ANÁLISIS DE DOS EJEMPLOS DE REESCRITURAS INFANTILES}

Las figuras 1 y 2 muestran un par de ejemplos de los textos escritos por un grupo de niños que desde el inicio de la alfabetización habían tenido la oportunidad de reescribir las historias que leían, releían, comentaban y recontaban con su profesora en el aula ${ }^{2}$. En este caso, se trata de la reescritura del álbum El túnel, de Anthony Browne. Estos dos ejemplos representan los textos que consiguieron escribir los niños de esta clase: unidades discursivas extensas, que representan las historias que recuentan de forma cohesiva y coherente, utilizando los recursos gráficos y discursivos propios de la escritura convencional de textos ${ }^{3}$.

Las reescrituras fueron realizadas por Eva y Jaime cuando tenían 7 años y finalizaban Segundo de Primaria en una escuela pública de la ciudad de Barcelona. Los textos fueron escritos en catalán, lengua oficial de la escolaridad en Cataluña.

\footnotetext{
${ }^{2}$ Estos dos textos forman parte de un corpus de escrituras colectadas en el seguimiento longitudinal de un grupo de niños que estuvieron expuestos durante los primeros años de Educación Primaria a secuencias de actividades de lectura, comentarios, recuento y reescritura de historias de libros de literatura infantil (Sepúlveda, 2012).

3 Estas características han sido el foco de nuestros análisis en trabajos anteriores (Sepúlveda, 2012; Teberosky y Sepúlveda, 2009).
} 


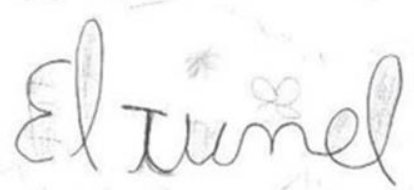

Hi taria una vagada un germa i una germans quena.s semblaban en res. La germana Dljia i sumiaba. El seu germa jelgaba amels siusames.

germa durnia prafean era denit el ser mena esquedabaderpertant ila surais de la mit, El ser germ escult a yigrapas: El ser germa es rusabels Arsar que salia ora ba a la reba abitasia. acala la de la coscla selva germana juga la pazien rar. un di gar ob ma juga justs. rensia iels la da se piba rarque en dentaban alli ancua dur ell vini aquet lbor men li diu:lla, Em la partil germa li diu

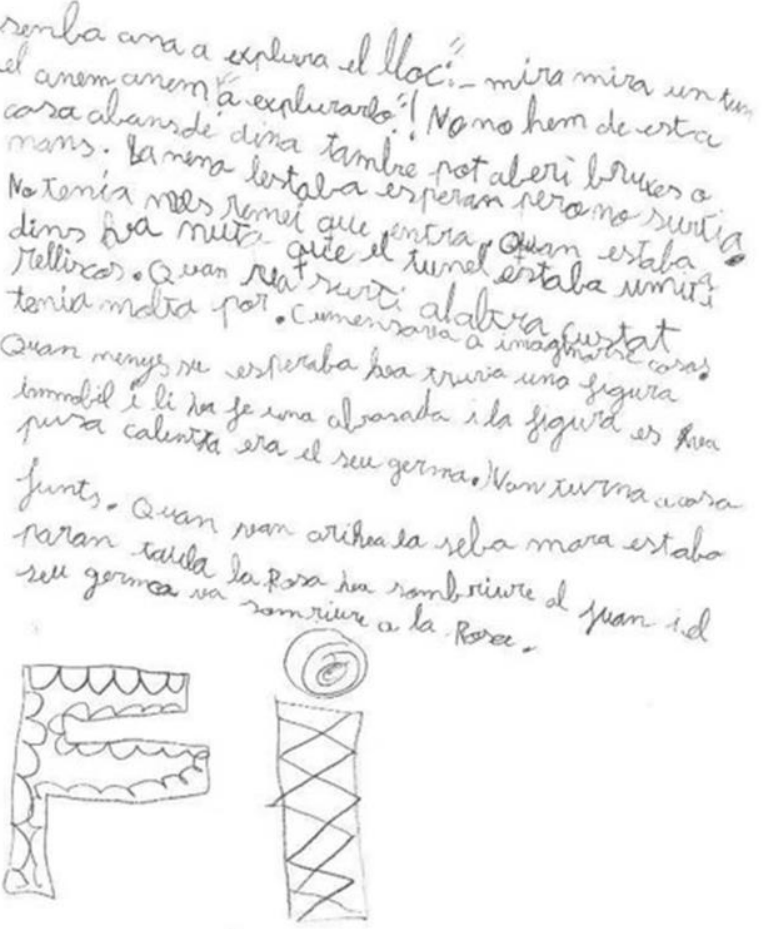

c

\section{Figura 1. Eva - 7 años, 2o Primaria - Reescritura del cuento "El túnel" de Anthony Browne}




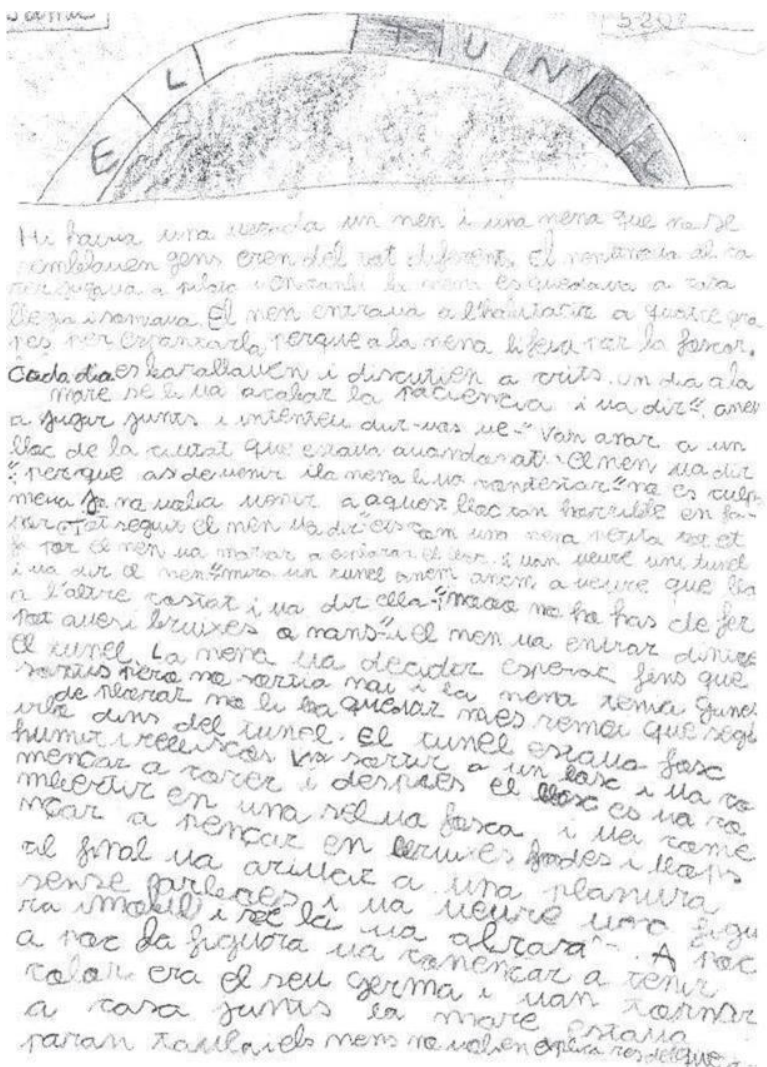

Figura 2. Jaime - 7 años, 2o Primaria - Reescritura del cuento “El túnel" de Anthony Browne

Con el objetivo de observar las estructuras utilizadas por Eva y Jaime en la reescritura de El túnel, hicimos una transcripción normalizada de sus textos; es decir, transcribimos las palabras escritas por los niños recuperando la ortografía convencional ${ }^{4}$, sin añadir ni suprimir elementos lexicales ni gramaticales y conservando las marcas de puntuación originales. Además, dispusimos el texto al modo del análisis en grille (Blanche-Benveniste, 1990), que alinea verticalmente los elementos que pertenecen a una misma categoría sintáctica. Así, en la columna central localizamos los participantes (sujetos o tema) de cada enunciado; a la izquierda las expresiones y marcadores discursivos que establecen las relaciones de comparación o de secuencia temporal o causal narradas, y a la derecha los sucesos descritos o relatados.

Para visualizar el lenguaje reproducido y el reformulado, en las transcripciones normalizadas dispuestas en grille que se observan en las tablas 1 y 2 hemos destacado con tipografía en negrita las palabras ${ }^{5}$ que reproducen literalmente formas del texto-fuente; y

\footnotetext{
4 Siguiendo el principio de "intervención mínima" (Ferreiro, et al.,1996, p. 28) hicimos corresponder a las formas escritas por los niños sus equivalentes formas convencionales, sin añadir ni suprimir elementos lexicales ni gramaticales (determinantes, pronombres) que afectaran la ortografía de la palabra en catalán. ${ }^{5}$ Palabras que denominamos formas, adoptando la terminología lingüística del análisis y que equivalen a palabras gráficas diferentes. En el estudio se identificaron las formas compartidas y las formas no compartidas entre los textos fuente y las reescrituras infantiles (textos resultantes).
} 
en tipografía de fuente normal las palabras que no coinciden con formas del texto-fuente y que constituyen reformulaciones, paráfrasis o adiciones hechas por los niños al reescribir el cuento.

Tabla 1. Eva -7 años, $2^{\underline{o}}$ Primaria -Transcripción normalizada dispuesta en grille, destaque formas compartidas

\begin{tabular}{|c|c|c|}
\hline $\begin{array}{r}\text { El túnel } \\
\text { Hi havia una vegada }\end{array}$ & $\begin{array}{l}\text { un germà i una } \\
\text { germana } \\
\text { La germana } \\
\text { El seu germà }\end{array}$ & $\begin{array}{l}\text { que no es semblaven en res. } \\
\text { llegia i somiava. } \\
\text { jugava amb els seus amics. }\end{array}$ \\
\hline $\begin{array}{r}\text { Quan era de nit } \\
\text { i } \\
\text { A pesar que } \\
\text { Un dia } \\
\text { i } \\
\text { Quan estaven allí }\end{array}$ & $\begin{array}{l}\text { a la seva mare } \\
\text { el nen } \\
\text { El germà }\end{array}$ & $\begin{array}{l}\text { dormia profundament } \\
\text { es quedava desperta escoltant els sorolls } \\
\text { de la nit. } \\
\text { es posava a } 4 \text { grapes i entrava a la seva } \\
\text { habitació. } \\
\text { sabia que la seva germana tenia por de la } \\
\text { foscor. } \\
\text { se li va acabar la paciència } \\
\text { els va dir aneu junts. } \\
\text { li diu:"-perquè hem de venir aquest lloc tan } \\
\text { fastigós" diu ell. } \\
\text { No és culpa meva li diu ella. Em fa por. } \\
\text { se'n va anar a explorar el lloc: } \\
\text { "- mira mira un túnel anem anem a } \\
\text { explorar-lo! " } \\
\text { No no hem de estar casa abans de dinar } \\
\text { també pot haver-hi bruixes o nans. } \\
\text { l'estava esperant però no sortia. } \\
\text { No tenia més remei que entrar. } \\
\text { va notar que el túnel estava humit i } \\
\text { relliscós. } \\
\text { tenia molta por. } \\
\text { Començava a imaginar-se coses. } \\
\text { va trobar una figura immòbil } \\
\text { li va fer una abraçada } \\
\text { es va posar calenta } \\
\text { era el seu germà. } \\
\text { Van tornar a casa junts. }\end{array}$ \\
\hline Quan van arribar & $\begin{array}{l}\text { la seva mare } \\
\text { la Rosa } \\
\text { el seu germà }\end{array}$ & $\begin{array}{l}\text { estava parant taula } \\
\text { va somriure al Juan } \\
\text { va somriure a la Rosa. }\end{array}$ \\
\hline
\end{tabular}

$\mathrm{Fi}$ 
Tabla 2. Jaime -7 años, 2o Primaria -Transcripción normalizada dispuesta en grille, destaque formas compartidas

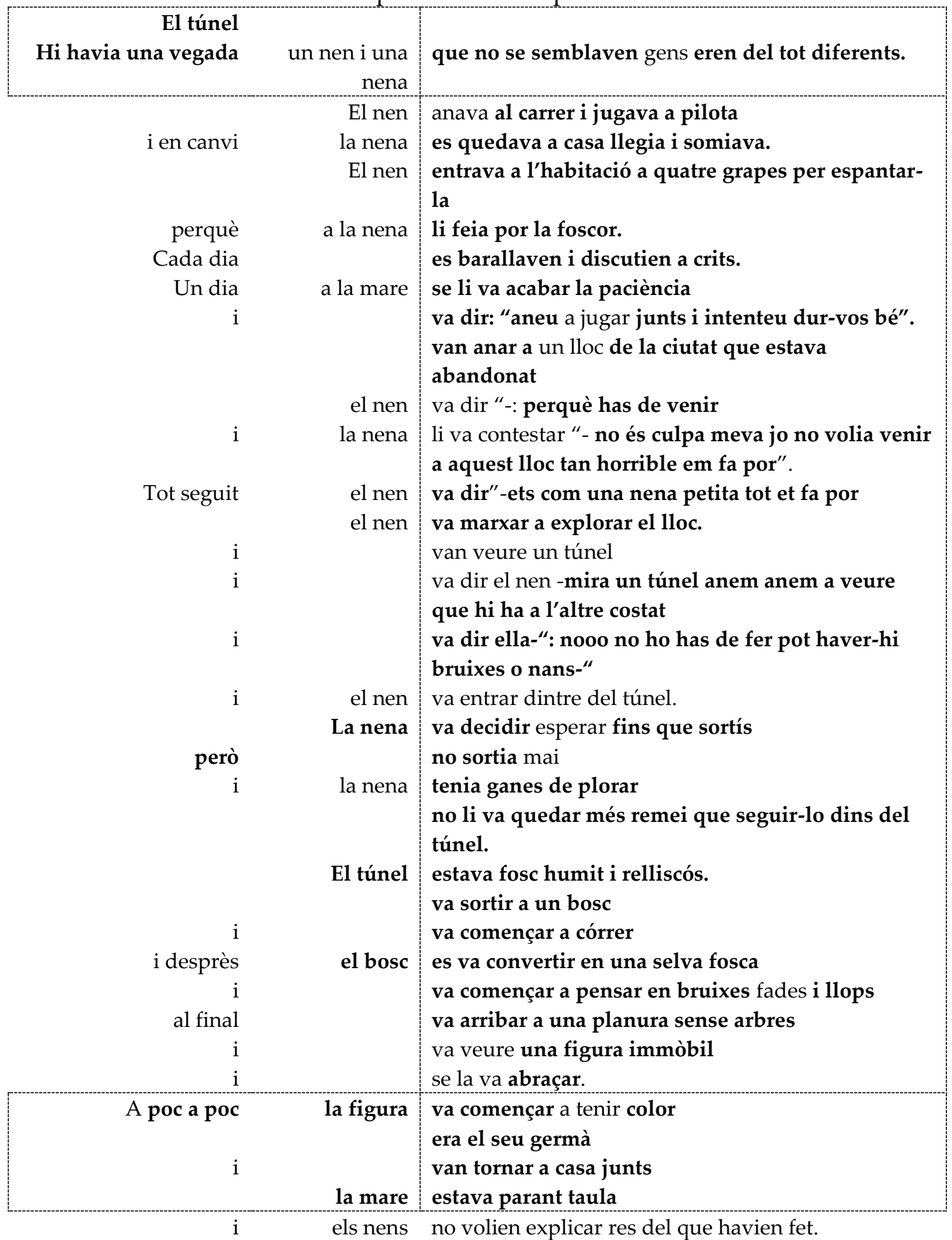

En general, esta organización y anotación de los textos pone de manifiesto que los niños reproducen, en una alta proporción, el léxico y estructuras del texto-fuente; y al 
mismo tiempo pone en evidencia el trabajo de reformulación realizado por ellos al intentar dicha reproducción. En las tablas podemos identificar que los niños tendieron, por una parte, a reproducir el lenguaje del texto fuente procedente del inicio y final del texto (enmarcado en las primeras y últimas filas), y de las acciones descritas y relatadas (predicados verbales segmentados en la tercera columna); $y$, por otra parte, que los niños tendieron a reformular el léxico de referencia de los personajes y las partículas cohesivas (destacados en la primera y segunda columna).

Observemos con detalle el lenguaje reproducido y el reformulado en ambos casos, acompañando el desarrollo de la historia, a partir de aquí referida como el texto fuente (TF).

Eva y Jaime comienzan sus textos reproduciendo el título y la fórmula de inicio "Hi havia una vegada" (Había una vez). En la Tabla 3 observamos que luego, Eva reproduce el léxico del texto-fuente para referir los personajes "un germà i una germana" (un hermano y una hermana), Jaime reformula y los refiere como "un nen i una nena". Los dos recuperan el argumento de apertura de la historia "que no es semblaven en res. Eren del tot diferents." (que no se parecían en nada. Eran del todo diferentes). Con una pequeña reformulación, Jaime usa una palabra sinónima y escribe: "que no se semblaven gens eren del tot diferents" (que no se parecían nada. Eran del todo diferentes).

Tabla 3. Comparación del texto fuente y dos reescrituras infantiles: la fórmula de inicio TF Hi havia una vegada un germà i una germana que no es semblaven en res.

Eren del tot diferents.

\begin{tabular}{lll}
\hline Eva & Hi havia una vegada un germà i una germana que no es semblaven en res. \\
\hline Jaime & Hi havia una vegada un nen i una nena & $\begin{array}{l}\text { que no se semblaven gens } \\
\text { eren el tot diferents. }\end{array}$ \\
\hline
\end{tabular}

Al seguir en la historia encontramos una secuencia descriptiva en la que se contrastan las características de los dos hermanos (ver Tabla 4):

Tabla 4. Comparación del texto fuente y dos reescrituras infantiles: presentación de los

\begin{tabular}{ll} 
& \multicolumn{1}{c}{ personajes } \\
\hline TF & La germana es quedava a casa, llegia i somiava. \\
& El germà jugava al carrer amb els seus amics: reia, saltava i jugava a pilota. \\
\hline Eva & La germana llegia i somiava. \\
& El seu germà jugava amb els seus amics. \\
\hline Jaime & El nen anava al carrer i jugava a pilota \\
& i en canvi la nena es quedava a casa llegia i somiava. \\
\hline
\end{tabular}

Eva recrea este paralelismo reproduciendo el léxico nominal de identificación de la referencia, germana y germà (hermana y hermano), y el léxico verbal de algunas de las acciones contrastadas, llegia, somiava, jugava (leía, soñaba, jugaba). Jaime reproduce un mayor número de estos elementos parafraseando el léxico nominal de referencia (nen, 
nena), un ítem verbal (anava) e introduciendo un marcador discursivo " $i$ en canvi" (y en cambio) que explicita la relación de contraste establecida entre las proposiciones.

La historia continúa contraponiendo los personajes (ver Tabla 5):

Tabla 5. Comparación del texto fuente y dos reescrituras infantiles: contraposición de los personajes

\begin{tabular}{|c|c|}
\hline $\mathrm{TF}$ & $\begin{array}{l}\text { Per la nit, ell dormia profundament a la seva habitació. } \\
\text { Ella es quedava desperta, al llit, escoltant els sorolls de la nit. } \\
\text { A vegades ell entrava a quatre grapes a l'habitació d'ella per espantar-la, } \\
\text { doncs sabia que a la seva germana li feia por la foscor. }\end{array}$ \\
\hline Eva & 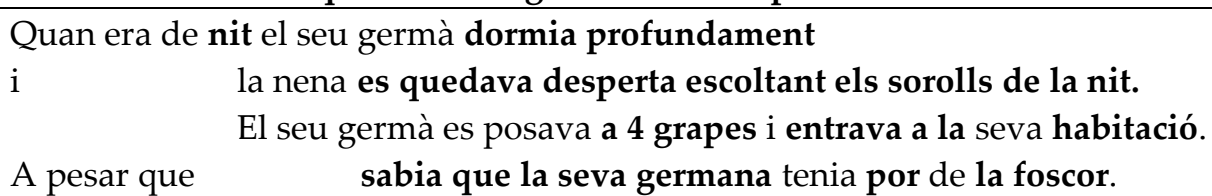 \\
\hline Jaime & $\begin{array}{l}\text { El nen entrava a l'habitació a quatre grapes per espantar-la } \\
\text { a la nena li feia por la foscor. }\end{array}$ \\
\hline
\end{tabular}

Si bien Eva reescribe este segmento reformulando los marcadores discursivos, conserva su localización a la izquierda de los enunciados. Así, observamos a la izquierda el marcador temporal: "Quan era de nit" (Cuando era de noche) que reformula como "Per la nit" (por la noche), y también el conector causal doncs (pues) lo reformula como A pesar que. A diferencia del texto fuente que utiliza los pronombres ell (él) y ella para hacer una referencia anafórica a los personajes, Eva repite el léxico de denominación en el caso de germà (hermano) y parafrasea germana (hermana) como nena en uno de los enunciados. El léxico verbal con el que narra las acciones descritas es reproducido de forma literal. En estos predicados reproducidos literalmente encontramos varios conjuntos de palabras que constituyen fórmulas, palabras que acostumbran a usarse juntas como es el caso de dormia profundament (dormía profundamente), els sorolls de la nit (los ruidos de la noche), por de la foscor (miedo de la noche).

Jaime, al igual que Eva, en lugar de referir los personajes mediante una anáfora pronominal, repite la paráfrasis por la que había optado, nen y nena; y también reformula el conector doncs (pues) utilizando perquè (porque), conservando su posición a la izquierda del enunciado. Reproduce literalmente el léxico de las acciones narradas y la locución "quatre grapes" (cuatro patas) y la colocación discutien a crits (discutían a gritos).

El siguiente segmento narra el evento que da lugar al inicio de la acción/aventura en la historia (ver Tabla 6): 
Tabla 6. Comparación del texto fuente y dos reescrituras infantiles: inicio de la acción

\begin{tabular}{|c|c|c|}
\hline \multirow[t]{2}{*}{$\mathrm{TF}$} & \multicolumn{2}{|c|}{ Quan estaven junts, } \\
\hline & Un matí, $\quad$ a & $\begin{array}{l}\text { a la seva mare se li va acabar la paciència. } \\
\text {-Aneu junts- els va dir- i intenteu dur-vos bé } \\
\text { i ser amables l'un amb l'altre al menys un cop, } \\
\text { i torneu a temps per dinar. }\end{array}$ \\
\hline Eva & $\begin{array}{l}\text { Un dia } \\
\text { i }\end{array}$ & $\begin{array}{l}\text { a la seva mare se li va acabar la paciència } \\
\text { els va dir aneu junts }\end{array}$ \\
\hline Jaime & $\begin{array}{l}\text { Cada dia } \\
\text { Un dia } \\
\text { i }\end{array}$ & $\begin{array}{l}\text { es barallaven i discutien a crits. } \\
\text { a la mare se li va acabar la paciència } \\
\text { va dir: "aneu a jugar junts i intenteu dur-vos bé". }\end{array}$ \\
\hline
\end{tabular}

Jaime reproduce el primer enunciado del segmento reformulando la expresión Cada dia como Quan estaven junts (Cuando estaban juntos). En las dos reescrituras observamos la reformulación del marcador temporal "Un matí" (una mañana) como "Un dia" y la conservación literal de las formas del texto fuente tanto para reproducir el discurso en narración como del discurso directo.

A partir de aquí Eva y Jaime pasan a reproducir una secuencia de diálogos entre los hermanos. En el primero encontramos (ver Tabla 7):

Tabla 7. Comparación del texto fuente y dos reescrituras infantiles: primer diálogo

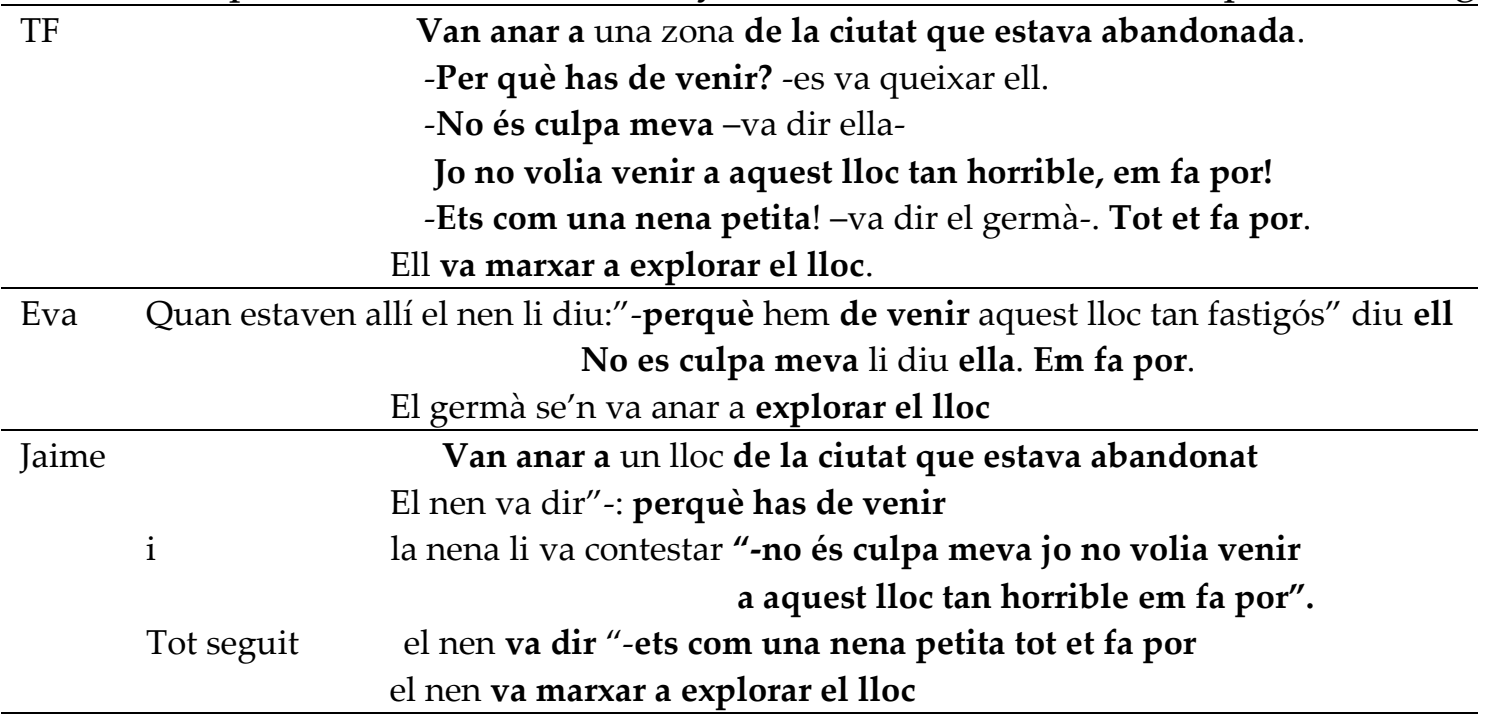

Eva comienza la reproducción de este segmento introduciendo una expresión de localización temporal y espacial, Quan estaven allí (Cuando estaban allí), y un marco antepuesto de cita para introducir el diálogo, el nen li diu (el niño le dice). También reformula la queja del hermano, Per què has de venir? - es va queixar ell, (Por qué has de venir? - se quejó él.), pasando la pregunta a la primera persona del plural y parafraseando el contenido de enunciados posteriores: Per què hem de venir aquest lloc tan fastigós" diu ell. (Por qué tenemos que venir a este lugar tan asqueroso" dice él.). A continuación, Eva 
reproduce segmentos literales de la intervención de la niña, que además también tienen el carácter de fórmulas: No es culpa meva li diu ella. Em fa por (No es mi culpa le dice ella. Me da miedo.)

A diferencia de Eva, Jaime inicia la reescritura de este segmento reproduciendo el enunciado que relata el desplazamiento de los niños a un lugar abandonado, Van anar a una zona de la ciutat que estava abandonada (Fueron a una zona de la ciudad que estaba abandonada). Jaime reproduce este segmento parafraseando el término zona como lloc (lugar) y estableciendo la concordancia de género correspondiente a este sustantivo. Al igual que Eva introduce los diálogos con marcos de citas antepuestos, incorporando en ocasiones partículas cohesivas, observamos el uso de la conjunción coordinante y en $i$ la nena li va contestar (y la niña le contestó), y en el siguiente enunciado el marcador temporal Tot seguit el nen va dir (A continuación el niño dijo). En esta reescritura las citas directas son reproducidas conservando las palabras del texto fuente.

El último enunciado del segmento es reproducido por los dos niños, los dos reformulan la referencia pronominal anafórica $E l l$ (Él) repitiendo el léxico de referencia a los personajes por el que habían optado en cada caso, Eva escribe El germà (El hermano) y Jaime El nen (El niño).

En la siguiente secuencia de diálogos encontramos (ver Tabla 8):

Tabla 8. Comparación del texto fuente y dos reescrituras infantiles: segundo diálogo

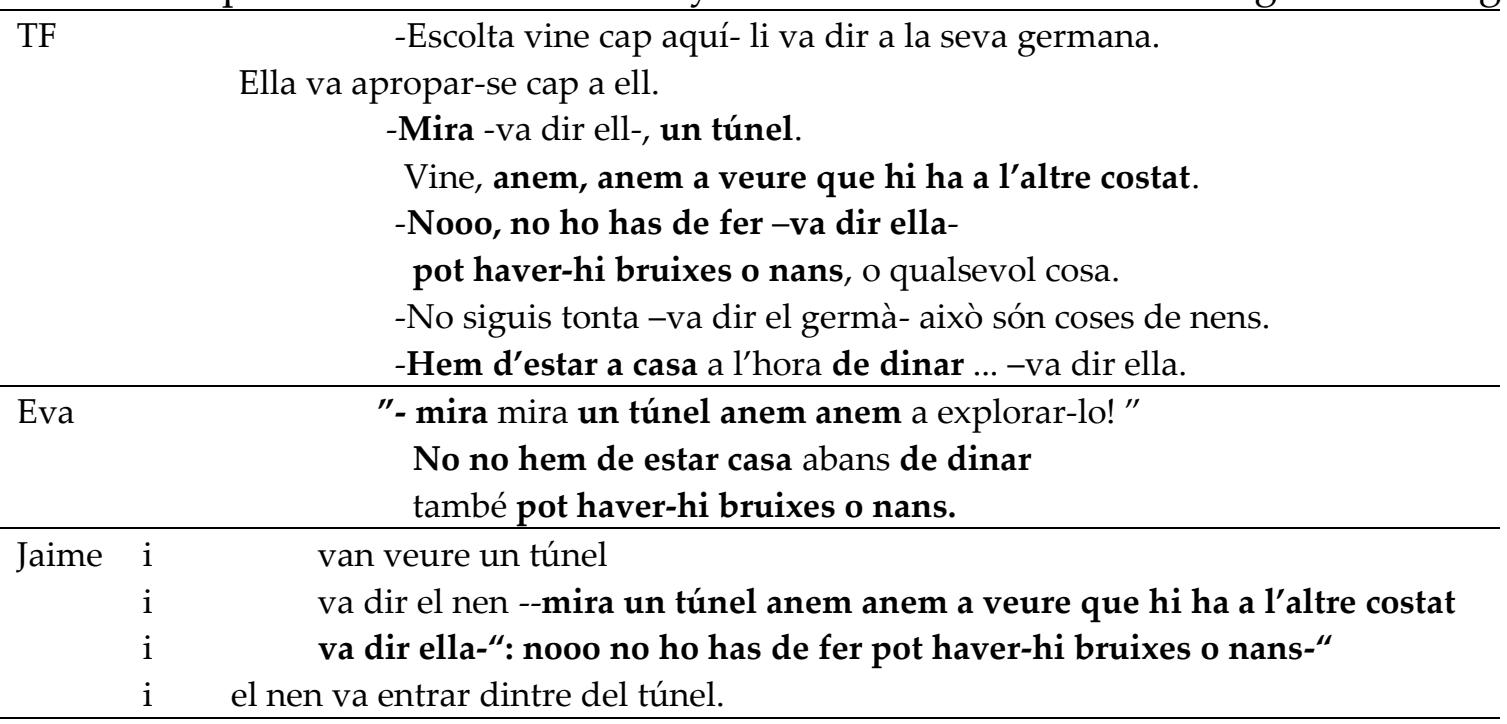

En este segmento Eva y Jaime reproducen de forma literal las palabras y expresiones dichas por los personajes. Las adiciones y reformulaciones las encontramos, en el caso de Eva, en la repetición de la palabra mira, mira, que antecede repeticiones lexicales que sí proceden del texto fuente: anem, anem (vamos, vamos) y Nooo, no; y en la introducción del adverbio també (también) para agregar un argumento a los expuestos antes. Jaime hace un mayor número de reformulaciones: pasa a discurso indirecto un 
evento narrado en discurso directo: $i$ van veure un túnel (y vieron un túnel) reformula Mira- va dir ell - un túnel (Mira -dijo él- un túnel); escribe marcos antepuestos para las citas directas, $i$ va dir el nen (y dijo el niño), narrando quién dice qué; y finaliza la reescritura del segmento incorporando un relato procedente de la imagen, $i$ el nen va entrar dintre del túnel (y el niño entró dentro del túnel).

A continuación tenemos una secuencia que relata las reacción emocional de la niña al evento anterior y la decisión que hace avanzar la acción narrativa (ver Tabla 9).

Tabla 9. Comparación del texto fuente y dos reescrituras infantiles: reacción emotiva

\begin{tabular}{lll} 
& \multicolumn{1}{c}{ del personaje } \\
\hline TF & i & $\begin{array}{c}\text { A la nena li feia por el túnel, } \\
\text { va decidir que esperaria fins que el seu germà sortís. }\end{array}$ \\
& i & \multicolumn{1}{c}{$\begin{array}{l}\text { Va esperar, però ell no sortia } \\
\text { ella tenia ganes de plorar, què podia fer? } \\
\end{array}$} \\
& No li va quedar més remei que seguir-lo per dins el túnel. \\
\hline Eva & $\begin{array}{l}\text { La nena l'estava esperant però no sortia } \\
\text { No tenia més remei que entrar. }\end{array}$ \\
\hline Jaime & La nena va decidir esperar fins que sortís però no sortia mai \\
& i & $\begin{array}{l}\text { la nena tenia ganes de plorar } \\
\text { no li va quedar més remei que seguir-lo dins del túnel. }\end{array}$ \\
\hline
\end{tabular}

Observamos que Eva parafrasea este segmento relatando la espera de la niña y la decisión de ir en busca de su hermano, reproduce de forma literal la referencia al personaje, la nena, el complemento de la contraposición "esperando" però no sortia (pero no salía) y la fórmula no tenir més remei que (no tener más remedio que). Jaime reproduce un mayor número de predicados y colocaciones fins que sortís (hasta que salga), tenia ganes de plorar (tenía ganas de llorar).

El libro continúa con la descripción de las características del túnel en una expresión enumerativa (ver Tabla 10).

Tabla 10. Comparación del texto fuente y dos reescrituras infantiles: descripción enumerativa

\begin{tabular}{lr}
\hline TF & El túnel estava fosc i humit i relliscós. \\
\hline Eva & Quan estava dins va notar que el túnel estava humit i relliscós. \\
\hline Jaime & El túnel estava fosc humit i relliscós. \\
\hline
\end{tabular}

Eva y Jaime reproducen la descripción enumerativa. La variación la observamos en el texto de Eva, que explicita información elidida en el texto e informada por la imagen, relatando que la niña Quan estava dins va notar que (Cuando estaba dentro notó que).

En la siguiente secuencia se narra lo que el personaje encontró del otro lado (ver Tabla 11). 
Tabla 11. Comparación del texto fuente y dos reescrituras infantiles: acciones y reacciones

\begin{tabular}{|c|c|c|}
\hline $\mathrm{TF}$ & Quan va sortir a l'altre costat & t es va trobar en mig d'un bosc tranquil. \\
\hline & & El seu germà no es veia enlloc \\
\hline & $\mathrm{i}$ & el bosc va convertir-se en una selva fosca. \\
\hline & & Va començar a pensar en llops i gegants i en bruixes, \\
\hline & $\mathrm{i}$ & volia tornar, però no podia. \\
\hline & & Què li passaria al seu germà si ella el deixava allí? \\
\hline & & Estava molt espantada, \\
\hline & i & va començar a córrer. \\
\hline Eva & Quan va sortir al altre costat & $\begin{array}{l}\text { tenia molta por. } \\
\text { començava a imaginar-se coses. }\end{array}$ \\
\hline Jaime & & va sortir a un bosc \\
\hline & i & va començar a córrer \\
\hline & i desprès & 1 bosc es va convertir en una selva fosca \\
\hline & i & va començar a pensar en bruixes fades i llops. \\
\hline
\end{tabular}

En la reescritura de Eva observamos que recupera de forma literal el marcador temporal Quan (Cuándo) y el predicado va sortir a l'altre costat (salió al otro lado), luego sintetiza y parafrasea el contenido del texto fuente escribiendo que la niña tenia molta por. Començava a imaginar-se coses. (tenía mucho miedo. Comenzaba a imaginarse cosas.), que en el texto-fuente puede vincularse a las expresiones va començar a pensar en llops $i$ gegants $i$ bruixes[...] estava molt espantada (comenzó a pensar en lobos y gigantes y brujas [...] estaba muy asustada).

Jaime reproduce de forma literal un mayor número de predicados verbales introduciendo reformulaciones como con el marcador temporal desprès (después) y la palabra fades (hadas) que aunque forma parte del campo semántico descrito con la enumeración llops i gegants $i$ bruixes (lobos y gigantes y brujas), no procede del texto fuente.

El relato continúa (ver Tabla 12):

Tabla 12. Comparación del texto fuente y dos reescrituras infantiles: acciones y

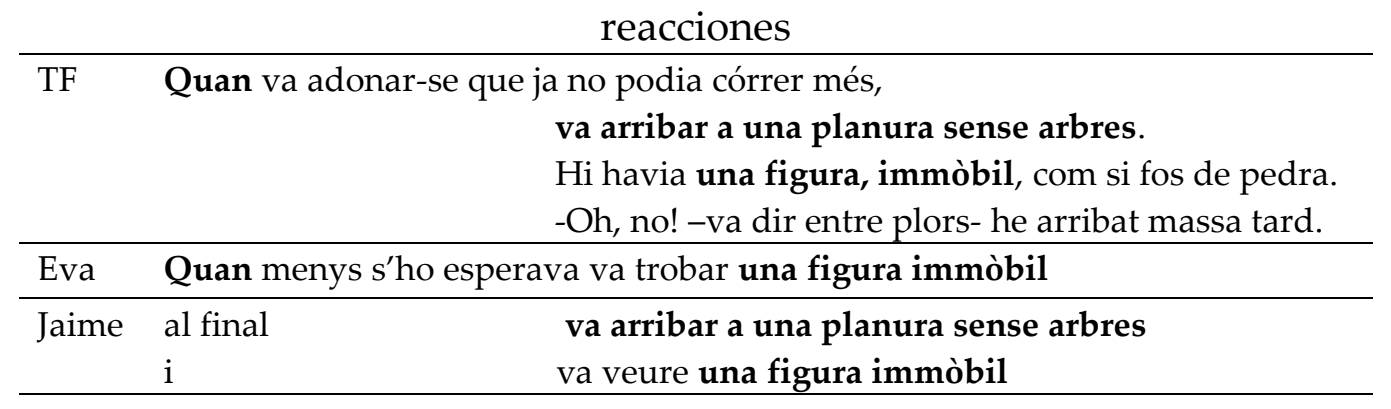

En las dos reescrituras encontramos referencia al encuentro de la niña con una figura inmóvil. Eva introduce una reformulación al comentar que este encuentro sucedió 
Quan menys s'ho esperava (Cuando menos se lo esperaba) y Jaime antecede la narración del evento recuperando uno anterior que incluye la colocación planura sense arbres (llanura sin árboles).

En el penúltimo episodio encontramos (ver Tabla 13),

Tabla 13. Comparación del texto fuente y dos reescrituras infantiles: penúltimo

\begin{tabular}{|c|c|c|}
\hline \multirow[b]{2}{*}{$\mathrm{TF}$} & & \\
\hline & $\begin{array}{l}\text { Poc a poc, la figu } \\
\text { i } \\
\text { Llavors, lentament, }\end{array}$ & $\begin{array}{l}\text { Va abraçar-se a la figura dura i freda mentre plorava. } \\
\text { ra va començar a canviar de color } \\
\text { s va fer més suau i més calenta. } \\
\text { va començar a moure's. } \\
\text { Era el seu germà. } \\
\text {-Rosa, jo sabia que vindries -li va dir. } \\
\text { Van córrer per tornar a casa, } \\
\text { van travessar la selva i varen creuar el bosc, } \\
\text { van entrar al túnel i van sortir junts. Junts els dos. }\end{array}$ \\
\hline Eva & la figı & $\begin{array}{l}\text { li va fer una abraçada } \\
\text { ra es va posar calenta } \\
\text { era el seu germà. } \\
\text { Van tornar a casa junts. }\end{array}$ \\
\hline Jaime & $\begin{array}{l}\mathrm{i} \\
\text { A poc a poc la fig } \\
\mathrm{i}\end{array}$ & $\begin{array}{l}\text { la va abraçar. } \\
\text { ra va començar a tenir color } \\
\text { era el seu germà } \\
\text { van tornar a casa junts }\end{array}$ \\
\hline
\end{tabular}

En las reescrituras este segmento está vinculado al segmento anterior al que conectan con la conjunción coordinante $i$ (y) y relatando el abrazo a la figura a través del uso de artículos y pronombres la, li (la, le) que aluden a la figura inmóvil recién citada. Eva y Jaime recuperan algunos de los efectos del abrazo, el cambio de color y temperatura, va començar a tenir color (comenzó a tener color), es va posar calenta (se puso caliente), y de forma literal la predicación Era el seu germà (Era su hermano) y el regreso a casa juntos.

En la secuencia final de la historia (ver Tabla 14) encontramos la reproducción literal de varios segmentos. Eva reproduce la expresión conectiva Quan van arribar (Cuando llegaron), la fórmula estava parant taula y el paralelismo del relato de intercambio de sonrisas entre los hermanos. En cambio, para terminar, Jaime introduce una inferencia escribiendo que els nens no volien explicar res del que havien fet (los niños no querían explicar nada de lo que habían hecho). 
Tabla 14. Comparación del texto fuente y dos reescrituras infantiles: último episodio

\begin{tabular}{lll}
\hline TF & Quan van arribar a casa seva, la seva mare estava parant taula. \\
& & - Hola -els va dir- trobo que esteu molt callats. \\
& & Va tot bé? \\
& & La Rosa va somriure el seu germà \\
& i & el Joan va somriure també la seva germana. \\
\hline Eva & Quan van arribar & la seva mare estava parant taula \\
& la Rosa va somriure al Juan \\
& i & el seu germà va somriure a la Rosa. \\
\hline Jaime & i & la mare estava parant taula \\
& &
\end{tabular}

\section{REFLEXIÓN}

En resumen, el análisis de los textos de Eva y Jaime nos permitió observar diversos procedimientos utilizados por los niños en sus reescrituras. Como habíamos descrito en trabajos anteriores, estos niños reprodujeron las palabras y expresiones localizadas en los límites del texto, en secuencias enumerativas, en el discurso directo y en el lenguaje formulario, y también reprodujeron los eventos del texto fuente conservando el léxico verbal. En cuanto a lo reformulado, identificamos paráfrasis del léxico de identificación de la referencia, adición de descripciones de las imágenes o comentarios sobre el texto, y la reformulación o introducción de marcadores discursivos para explicitar las relaciones de contraste o de secuencia temporal o causal establecidas entre los eventos; en este último caso, si bien observamos en ocasiones la reformulación de los marcadores discursivos, los niños conservaron su significado y localización a la izquierda de los enunciados, reproduciendo su función como delimitadores internos del continuo textual. Detengámonos en cada uno de estos aspectos.

\section{Lo reproducido de forma literal (o parcialmente literal) del texto-fuente}

Un texto constituye una pieza de discurso que, aun siendo lineal, tiene partes (está dividido) y, por tanto, es estructural (Hoey, 2004). Veamos qué partes son reproducidas por los aprendices.

Los límites del texto: título, inicio, final y la localización en el texto de los marcadores discursivos

Para un niño que comienza a aprender a leer y escribir, hay partes del texto que sobresalen en los límites del espacio gráfico y que son identificadas inicialmente por la separación entre título y texto y entre su comienzo y final (Ferreiro, et al., 1996). Pero hay otras localizaciones que también pueden tener relevancia, aunque gráficamente no sean visibles: se trata de cierta preferencia de ocurrir al comienzo de los enunciados gráficos y de otras de localizarse al final del texto (Hoey, 2004). Esta relación entre localización 
gráfico-espacial y formas discursivas es identificada también por los niños. En los textos infantiles que aquí analizamos ocurre justamente esa diferenciación, a semejanza del texto-fuente.

Respecto a los límites externos del texto, en un comienzo los niños usan procedimientos de delimitación desde lo externo hacia lo interno del texto, a partir del título y el comienzo formulario hasta el final, también formulario. Estos aspectos son el "rostro gráfico" del texto que, según Ferreiro et al. (1996), sirve para dar unidad al texto.

Por otra parte, si observamos la puntuación usada por los niños vemos que muchos conectores se ubican a la izquierda del enunciado: así por ejemplo Eva escribe "Quan era de nit" (Cuando era de noche), "A pesar que", "Un dia", "Quan estaven alli" (Cuando estaban allí), etc. y Jaime escribe "Cada dia", "Un dia", "Tot seguit", etc. a la izquierda del enunciado. Hay aquí una cierta homologación entre localización gráficoespacial y formas discursivas. Esa homologación se puede explicar por el principio de iconicidad, enunciado por Diessel (2008), que sostiene que este principio predice que la posición de las cláusulas adverbiales refleja el orden secuencial de los eventos que describe. En el caso de las cláusulas temporales indican un evento previo que precede a la cláusula principal.

\section{El léxico verbal que refiere los eventos de la historia}

217 Otra de las características de los textos reescritos por los niños es la asombrosa semejanza del léxico verbal respecto al texto-fuente. Los estudios en adquisición del lenguaje oral habían sugerido que en la elección del verbo suele haber una tendencia a repetir el léxico del input previamente activado. El estudio de Rowland et al. (2012) muestra que las representaciones y conexiones entre los verbos de la fuente y los verbos reproducidos están indicando, además, una semejanza en la estructura sintáctica y en el uso de argumentos que especifican dichas estructuras en las cuales pueden ocurrir los verbos. Así también, Pickering y Branigan (1998) habían mostrado que, en adultos, la estructura sintáctica está influenciada por la activación de la estructura del input.

Además del léxico, los niños mantienen la alternancia entre los tiempos verbales: un verbo en tiempo de pasado perifrástico ${ }^{6}$ van arribar (llegaron) y otro en imperfecto estava (estaba). Es decir, un tiempo de referencia exofórica respecto al tiempo de la enunciación, con referencia fuera del discurso, y otro de referencia anafórica dentro del discurso (Cuenca, 2010).

\section{El lenguaje formulario}

La reproducción del lenguaje formulario, en una combinación de al menos dos palabras, es otra de las apropiaciones de los niños en sus textos. En las reescrituras analizadas

\footnotetext{
${ }^{6}$ En catalán el pasado perifrástico se forma con un verbo auxiliar.
} 
observamos que los niños reprodujeron tanto las expresiones formularias (había una vez, a cuatro patas, acabar la paciencia) como las secuencias de palabras que tienden a co-ocurrir en los usos del lenguaje (no es mi culpa, discutir a gritos, miedo de la oscuridad, ganas de llorar).

El lenguaje formulario muestra una preferencia a otra combinación alternativa, que podría ser equivalente, pero que no ha estado convencionalizada (Erman y Warren, 2000). Un gran número de estudios impulsados por los análisis de corpus han señalado la co-ocurrencia de palabras. Esta co-ocurrencia se ha denominado "paquetes" (Biber, 2005), "chunks" (O'Keeffe et al., 2007), "clusters" (Tribble, 2006) y lenguaje formulario (Bannard y Lieven, 2012; Erman y Warren, 2000). Las características del lenguaje formulario pueden estar en relación con el hecho de que el significado de la expresión no es equivalente a la suma del significado de los componentes, o a que las frases presentan una restricción de intercambio, por ejemplo, los miembros no pueden ser reemplazados por sinónimos y hay una restricción de variación sintáctica.

En lo que respecta a la adquisición del lenguaje oral, Peters (1983) ya había considerado que el niño desarrolla estrategias para la extracción significativa de estos trozos en el flujo de la conversación: es capaz de recordarlos, compararlos con otros y usarlos como unidades de nuevo léxico. Más tarde, el niño podrá analizar los fragmentos almacenados y luego reconocer y recordar los patrones estructurales y los modos de distribución. Del mismo modo, en el caso de los textos escritos se reconocen secuencias de fórmulas de acuerdo con los géneros y las temáticas.

Las secuencias enumerativas y la repetición lexical

Los textos que los niños reescriben muestran una tendencia a conservar la calidad y cantidad de las enumeraciones del texto-fuente. En estudios previos (Sepúlveda, 2012) ya habíamos observado que la estructura yuxtapuesta del léxico en secuencias enumerativas o en las repeticiones lexicales parece facilitar su conservación.

Así, en la reproducción de El túnel, la serie de acciones adjudicadas a la niña de quedarse en casa, leer y soñar (en catalán: es quedava a casa, llegia i somiava), la serie de adjetivos con que se describe el túnel oscuro, húmedo y resbaloso (fosc, humit i relliscós) o de sustantivos que describen los pensamientos de la niña en lobos, gigantes y brujas (pensar en llops, gegants i en bruixes). También, las repeticiones lexicales que imitan el habla de conversación entre los personajes y que garantizan la representación de su dramatismo. En los ejemplos analizados los niños reproducen el Ven, vamos, vamos a ver que hay al otro lado (Vine, anem, anem a veure que hi ha a l'altre costat) y el Nooo, no lo hagas (Nooo, no ho has de fer) de los diálogos del texto-fuente.

\section{El discurso directo}

Hemos observado que con la reproducción escrita de discurso directo los niños desarrollan procedimientos lingüísticos y gráficos para delimitar internamente las 
unidades del texto. En este proceso de delimitación, el discurso directo es una unidad que puede ser extraída del resto del texto, imitada y citada. Este proceso comienza con el lenguaje oral como una forma de "hablar del lenguaje" (como lo denominan Bonnet y Tamine-Gardes, 1984); es decir, desarrollar una conciencia sobre el acto de habla, al mencionar el acto de citar, al tratar las palabras citadas como signos y dar alternancia al diálogo cuando hay más de un locutor.

Los niños tendieron a reproducir de forma literal las palabras y expresiones procedentes del habla de los personajes. Como sostienen algunos estudiosos (Olson y Hildyard, 1983), en el discurso directo se cita no sólo el significado de lo dicho sino también las mismas palabras de lo dicho, las palabras atribuidas al reportado. En un estudio anterior, habíamos mostrado que el discurso directo es una unidad segmentable dentro del texto, una parte que tiene límites y que los niños consiguen reconocer y que intentan indicar en sus representaciones escritas (Sepúlveda, 2012; Sepúlveda y Teberosky, 2014; Teberosky y Sepúlveda, 2019).

\section{Lo reformulado por paráfrasis}

$\mathrm{Al}$ intentar reproducir el texto, reescribiéndolo, los niños lo reformularon. Produjeron sus propias versiones parafraseando el sistema de referencia a los personajes, parafraseando la acción, parafraseando o introduciendo enlaces para secuenciar temporal y causalmente la acción, así como añadiendo comentarios procedentes de la descripción de las imágenes o del comentario del texto. Veamos esas reformulaciones:

\section{Paráfrasis del léxico de identificación de la referencia}

A diferencia del texto fuente que alterna la anáfora léxica con la gramatical a través del uso de pronombres (ell, ella), los niños en sus reescrituras tendieron a usar la anáfora léxica repitiendo los términos referenciales por los que habían optado germà, germana o nen, nena (hermano, hermana, niño, niña). Así observamos que los niños prefirieron optar por procedimientos de cohesión léxica en lugar de usar términos de carácter gramatical al modo del texto-fuente.

\section{Paráfrasis o adición de enlaces temporales y causales}

Los conectores temporales que usan los niños no son iguales a los del texto-fuente, pero conservan el significado temporal y la posición respecto a la cláusula principal. En los textos analizados, todos los conectores temporales se localizan antes de las cláusulas principales, en cambio los conectores causales tienden a presentar una posición posterior.

Como ya mencionamos, los dos ejemplos analizados fueron producidos por niños que desde el inicio de la escolaridad primaria habían tenido la oportunidad de escuchar, comentar y reescribir historias de libros de literatura infantil. Entre las actividades de 
comentario realizadas por la profesora (Sepúlveda, 2012) hemos de destacar la atención a las palabras y expresiones que ponen en relación los eventos o diferentes segmentos del texto-fuente: marcadores discursivos, referidos en el aula inicialmente como "palabras para enganchar". A través de diferentes lecturas de cuentos, los niños de esta clase fueron coleccionando ejemplos de marcadores discursivos dispuestos en listas murales que podían ser consultadas en los momentos de escritura de textos. Atribuimos a esta intervención educativa la diversidad de conectores utilizados por los niños en sus textos. Como observamos en los ejemplos aquí analizados, los niños reformularon los marcadores discursivos del texto fuente o los introdujeron en lugares en los que no estaban explícitos.

La extracción y disposición en lista de los marcadores discursivos que conectaban temporal y causalmente los eventos de la historia contribuyó a la conceptualización de esta unidad textual fijando de modo paradigmático las opciones/recursos disponibles de esta categoría que ofrece la lengua para la producción de textos.

\section{Paráfrasis de la acción}

Si bien observamos que los niños tendieron a reproducir el léxico verbal con el que se narra la acción, también hemos documentado paráfrasis. Así por ejemplo los niños escriben anava al carrer (iba a la calle) en lugar de jugava al carrer (jugaba en la calle), va dir (dijo) en lugar de es va queixar (se quejó), estava esperant (estaba esperando) en lugar de va esperar (esperó). En cada caso se podrían hacer interpretaciones relacionadas con la familiaridad con el léxico del texto-fuente o su grado de complejidad; sin embargo, destacamos que estos procedimientos ponen de manifiesto que el producto de una reescritura no es una copia literal del texto, ni de "memoria", sino que es una producción.

Como hemos argumentado en investigaciones anteriores (Sepúlveda, 2012), la actividad de reescritura pone en marcha procedimientos de reproducción del lenguaje tales como la reproducción literal, la paráfrasis, el comentario o la reformulación que han sido descritos como verdaderos mecanismos de aprendizaje del lenguaje (Martinot, 2000, 2003). En los dos textos analizados, aproximadamente el $20 \%$ de las palabras usadas por los niños no se corresponden literalmente con palabras del texto fuente. Este porcentaje resulta de la cuantificación del total de palabras del texto de cada niño que no se corresponden literalmente con palabras del texto-fuente.

\section{La incorporación de descripciones procedentes de las imágenes o del comentario del texto}

$\mathrm{Al}$ representar el texto fuente, los niños incluyeron informaciones derivadas de otras "fuentes" como las imágenes del libro, los comentarios hechos en el aula, así como los comentarios y descripciones de su propia comprensión, síntesis o interpretación de los diferentes eventos de la historia. Por ejemplo, Eva escribe "cuando [la niña] salió al otro 
lado [del túnel] tenía mucho miedo, comenzó a imaginarse cosas" sintetizando lo que el libro cuenta a través de dos párrafos en los que se describe:

Del otro lado ella se encontró en medio de un bosque tranquilo. No había ni rastro de su hermano. Pero el bosque pronto se convirtió en una selva oscura.

Empezó a pensar en lobos y gigantes y en brujas, y quería regresarse, pero no podía. ¿Qué sería de su hermano si ella se regresara? Ya estaba muy asustada_y empezó a correr, más y más aprisa cada vez. (Browne, 1989/2001).

\section{CONCLUSIÓN}

\section{Aprendizaje por imprimación léxica y sintáctica}

En resumen, las reescrituras analizadas se componen a partir de un juego entre reproducción y reformulación del lenguaje del texto-fuente en el proceso de apropiación del lenguaje escrito ¿Cómo pudieron estos niños retener tantos elementos de las historias escuchadas y comentadas en el aula?

La situación didáctica expuso a estos niños a participar en lecturas, comentarios y relecturas del texto por ser reescrito, pero dicha situación no tenía la intención, ni buscaba de forma explícita, un aprendizaje de memoria o literal del texto. Por esto, pensamos que debemos considerar mecanismos de aprendizaje implícito que contribuyen a comprender la reutilización del léxico y de las estructuras sintácticas escuchadas.

Los estudios sobre el desarrollo del lenguaje han demostrado que la frecuencia y la similitud entre el lenguaje al que se expone al niño y el lenguaje que tiene oportunidad de usar son importantes en la adquisición de construcciones infantiles tempranas. En el enfoque basado en el uso para la adquisición del lenguaje (oral y escrito), el desarrollo gramatical está determinado por la experiencia del niño con la lengua. Específicamente, la frecuencia de la ocurrencia en el input de las diferentes estructuras lingüísticas juega un papel importante en este enfoque. Cada vez que un niño encuentra una expresión lingüística en la lengua del ambiente, ésta deja un rastro en su memoria que refuerza su representación mental (lo que hemos mencionado como "atrincheramiento" o sea el afianzamiento de una unidad lingüística como patrón cognitivo o de rutina en la mente del usuario de la lengua (Tomasello, 2003), que a su vez facilita la activación de la expresión en el uso futuro de la lengua, su imprimación.

En el caso de la actividad de reescritura de cuentos escuchados y comentados en el aula, el lenguaje input (lo que escuchan los niños) coincide con el lenguaje por ser usado (el lenguaje por ser escrito). También es necesario considerar el efecto de frecuencia que se da en el ciclo de actividades de lectura, comentario, relectura, recuento, reescritura. 


\section{Implicaciones para la práctica educativa de enseñar desde el uso del lenguaje escrito}

En el estudio de intervención longitudinal (Sepúlveda, 2012) del que proceden los textos infantiles analizados en este artículo, teníamos el objetivo de promover el aprendizaje del lenguaje escrito con la actividad de reescritura de cuentos, tanto desde el punto de vista gráfico como desde el punto de vista discursivo. Como hemos reiterado, el uso de las mismas palabras del texto no fue en absoluto estimulado por la profesora, entre otros motivos por la mala prensa que tiene la reproducción literal, desde hace mucho tiempo, como ejemplo de aprendizaje memorístico. Influidas por la perspectiva narrativa esperábamos que los niños aprendieran los aspectos más estructurales, o en términos de Genette (1991/1993), de la ficción más que de la dicción. Por ejemplo, el esquema de la historia y algunas formas de expresión. Pero nuestra sorpresa fue grande al ver que a medida que avanzábamos en la práctica de la reescritura, los niños podían reproducir literalmente el léxico y las construcciones del texto-fuente, además del esquema de la historia.

Para explicar este efecto de imprimación que la reescritura había suscitado, nos fue absolutamente necesario pensar desde el uso, en la frecuencia, el papel del lenguaje dirigido a los niños (input) y de las oportunidades ofrecidas para usarlo (output), así como la importancia del objetivo de la actividad ("pensar en el texto para reescribirlo"). Al pensar no solo en los aspectos más generales del aprendizaje, sino en los aspectos más específicos del léxico y las construcciones del texto, pudimos ver los procedimientos de los niños en la reproducción, así como los aspectos del texto que apoyan materialmente (gráficamente) dicha reproducción.

Esta experiencia con reescritura de textos fuente nos ha hecho reflexionar sobre las diferencias y semejanzas entre aprender la lengua oral y la escrita: si el diálogo y la interacción dialógica es la base del aprendizaje oral, la lectura en voz alta y la visualización del texto es la base del aprendizaje de la lengua escrita, sin excluir el diálogo, pero esta vez hablando "sobre" el texto en la interacción con los alumnos y para escribir.

De ahí la importancia de optar en la práctica educativa por secuencias de actividades que permitan un uso intensivo del lenguaje escrito y los textos. Proponemos considerar el conjunto de tareas encadenadas que incluyen la lectura en voz alta expresiva de la profesora dirigida a los niños y la visualización conjunta del libro leído, los comentarios y recuentos orales, la elaboración de listas a partir de los textos leídos y la producción de (re)escrituras (Teberosky y Sepúlveda, 2018; Teberosky et al., 2020; Teberosky, en prensa). 


\section{REFERENCIAS}

Bannard, C., y Lieven, E. (2012). Formulaic Language in L1 Acquisition. Annual Review of Applied Linguistics, 32, 3-16. https://doi.org/10.1017/S0267190512000062.

Bernicot, J., Hudelot, C., y Salazar Orvig, A. (2006). Avant-propos : La reprise et ses fonctions. La Linguistique, 42(2), 3-8. https://doi.org/10.3917/ling.422.0003.

Biber, D. (2005). Paquetes léxicos en textos de estudio universitario: variación entre disciplinas académicas. Revista Signos, 38(57), 19-29. https://doi.org/10.4067/s071809342005000100002.

Blanche-Benveniste, C. (1990). Un modèle d'analyse syntaxique «en grilles» pour les productions orales. Anuario de Psicología, (47), 11-28. https://bit.ly/3cvbtm6.

Bonnet, C., y Tamine-Gardes, J. (1984). Quand l'enfant parle du langage. Pierre Mardaga.

Browne, A. (2001). El Túnel (Il. A. Browne, Trad. C. Esteva). Fondo de Cultura Económica. (Obra original publicada en 1989 bajo el título de The Tunnel).

Chouinard, M., y Clark, E. (2003). Adult reformulations of child errors as negative evidence. Journal of Child Language, 30(3), 637-669. https://doi.org/10.1017/s0305000903005701.

Clark, E. (1993). The Lexicon in Acquisition. https://doi.org/10.1017/CBO9780511554377. Cuenca, M.J. (2010). Gramática del Texto. Arco/Libros.

De Weck, G. (2000). Reformulations et répétitions par les adultes du langage des enfants : comparaison de dialogues avec des enfants normaux et dysphasiques. Langages, 34(140), 38-67. https://doi.org/10.3406/lgge.2000.2390.

Diessel, H. (2008). Iconicity of sequence: A corpus-based analysis of the positioning of temporal adverbial clauses in English. Cognitive Linguistics, 19(3), 465-490. https://doi.org/10.1515/COGL.2008.018.

Elbers, L. (2000). An output-as-input hypothesis in language acquisition. En P. Broeder y J. Murre (Eds.), Models of Language Acquisition: Inductive and Deductive Approaches (pp. 244-271). Oxford University Press.

Ellis, R., y Sheen, Y. (2006). Reexamining the role of recasts in second language acquisition. Studies in Second Language Acquisition, 28(4), 575-600. https://doi.org/10.1017/s027226310606027x.

Erman, B., y Warren, B. (2000). The idiom principle and the open choice principle. Text $\mathcal{E}$ Talk, 20(1), 29-62. https://doi.org/10.1515/text.1.2000.20.1.29.

Ferreiro, E. (2002). Escritura y oralidad: unidades, niveles de análisis y conciencia metalingüística. En E. Ferreiro (Ed.), Relaciones de (in)dependencia entre oralidad y escritura (pp. 151-172). Gedisa.

Ferreiro, E., Pontecorvo, C., Ribeiro, N., y García, I. (1996). Caperucita Roja aprende a escribir: Estudios psicolingüísticos comparativos en tres lenguas. Gedisa. 
Genette, G. (1993). Ficción y dicción (Trad. C. Manzano). Lumen. (Obra original publicada en 1991 bajo el título de Fiction et diction. Seuil).

Hoey, M. (2004). Textual colligation: a special kind of lexical priming. En K. Aijmer y B. Altenberg (Eds.), Advances in Corpus Linguistics (pp. 169-194). https://doi.org/10.1163/9789004333710_011.

Kara, M. (Dir.). (2007). Usages et analyses de la reformulation. Université de Metz.

Keenan, E. (1975). Making It Last: Repetition in Children's Discourse. Proceedings of the First Annual Meeting of the Berkeley Linguistics Society, 279-294. https://doi.org/10.3765/bls.v1i0.2336.

Martinot, C. (2000). Étude comparative des processus de reformulations chez des enfants de 5 à 11 ans. Langages, 34(140), 92-123. https://doi.org/10.3406/lgge.2000.2392.

Martinot, C. (2003). Pour une linguistique de l'acquisition la reformulation : du concept descriptif au concept explicatif. Langage et Société, 2003/2(104), 147-151. https://doi.org/10.3917/1s.104.0147.

O'Keeffe, A., McCarthy, M., y Carter, R. (2007). From Corpus to Classroom: Language Use and Language Teaching. Cambridge University Press.

Olson, D., y Hildyard, A. (1983). Literacy and the comprehension and expression of literal meaning. En F. Coulmas y K. Ehlich (Eds.), Writing in Focus (pp. 291-326). https://doi.org/10.1515/9783110822830.291.

Pappas, C., y Brown, E. (1987). Young Children Learning Story Discourse: Three Case Studies. The Elementary School Journal, 87(4), 455-466. https://doi.org/10.1086/461508.

Peters, A. (1983). The Units of Language Acquisition. Cambridge University Press.

Peytard, J. (1984). Problématique de l'altération des discours: reformulation et transcodage. Langue française, (64), 17-28. https://doi.org/10.3406/lfr.1984.5201.

Pickering, M., y Branigan, H. (1998). The Representation of Verbs: Evidence from Syntactic Priming in Language Production. Journal of Memory and Language, 39(4), 633-651. https://doi.org/10.1006/jmla.1998.2592.

Puranik, C., Lombardino, L., y Altmann, L. (2007). Writing through retellings: an exploratory study of language-impaired and dyslexic populations. Reading and Writing, 20, 251-272. https://doi.org/10.1007/s11145-006-9030-1.

Rowland, C., Chang, F., Ambridge, B., Pine J., y Lieven, E. (2012). The development of abstract syntax: Evidence from structural priming and the lexical boost. Cognition 125(1), 49-63. https://doi.org/10.1016/j.cognition.2012.06.008.

Rubin, D. (1995). Memory in Oral Traditions: The Cognitive Psychology of Epic, Ballads, and Counting-out Rhymes. Oxford University Press.

Savage, C., Lieven, E., Theakston, A., y Tomasello, M. (2006). Structural Priming as Implicit Learning in Language Acquisition: The Persistence of Lexical and Structural Priming in 4-Year-Olds. Language Learning and Development, 2(1), 27-49. https://doi.org/10.1207/s15473341lld0201_2. 
Sepúlveda, A. (2012). El aprendizaje inicial de la escritura de textos como (re)escritura. (Tesis de doctorado). Universidad de Barcelona. http://hdl.handle.net/2445/42727.

Sepúlveda, A., y Teberosky, A. (2011). El lenguaje en primer plano en la literatura infantil para la enseñanza y el aprendizaje inicial del lenguaje Escrito. Cultura y Educación, 23(1), 23-42. https://doi.org/10.1174/113564011794728560.

Sepúlveda, A., y Teberosky, A. (2014). La citación en el aprendizaje inicial de la escritura de textos. Enunciación, 26-38. https://doi.org/10.14483/udistrital.jour.enunc.2014.1.a02.

Swain, M. (1995). Three functions of output in second language learning. En G. Cook y B. Seidlhofer (Eds.), Principles and Practice in Applied linguistics: Studies in honour of $\mathrm{H}$. G. Widdowson (pp. 125-144). Oxford University Press.

Tannen, D. (1987). Repetition in conversation as spontaneous formulaicity. Text $\mathcal{E}$ Talk, 7(3), 215-244. https://doi.org/10.1515/text.1.1987.7.3.215.

Teberosky, A. (1992). Aprendiendo a escribir. Ice/Horsori.

Teberosky, A. (en prensa). Palabras a las profesoras que enseñan a leer y a escribir. Editorial Santillana.

Teberosky, A., y Sepúlveda, A. (2009). El texto en la alfabetización inicial. Infancia y Aprendizaje, 32(2), 199-218. https://doi.org/10.1174/021037009788001770.

Teberosky, A., y Sepúlveda, A. (2018). Aprender a partir de la lectura en voz alta del adulto. Revista entreideias, 7(2), 73-90. https://doi.org/10.9771/re.v7i2.25327.

Teberosky, A., y Sepúlveda, A. (2019). A construção infantil das unidades do texto. En A. Galvão y J. Correa (Org.), A escrita de textos por crianças: limites, possibilidades e implicações educacionais (pp. 15-41). Vetor Editora.

Teberosky, A., Sepúlveda, A., y Costa e Sousa, O. (2020). Orality, Reading and Writing in Early Literacy. En R. Alves, T. Limpo y R. Joshi (Eds.) Reading-writing connections: Towards Integrative Literacy Science (pp. 85-105). https://doi.org/10.1007/978-3-03038811-9_6.

Tomasello, M. (1992). First Verbs: A case study of early grammatical development. Cambridge University Press.

Tomasello, M. (2003). Constructing a Language: A Usage-Based Theory of Language Acquisition. Harvard University Press.

Tribble, C. (2006). English for academic purposes: Building an account of expert and apprentice performances in literary criticism. En M. Scott y C. Tribble, Textual Patterns: Key Words and Corpus Analysis in Language Education (pp. 131-159). https://doi.org/10.1075/scl.22.

Veneziano, E., Sinclair, H., y Berthoud, I. (1990). From one word to two words: repetition patterns on the way to structured speech. Journal of Child Language, 17(3), 633-650. https://doi.org/10.1017/s0305000900010928. 